\title{
PREJUÍZOS PSICOSSOCIAIS CAUSADOS PELO VITILIGO: A IMPORTÂNCIA DE UM OLHAR PARA O CORPO
}

\section{ARTIGO ORIGINAL}

ROCHA, Marizete Oliveira ${ }^{1}$

MARTINS, Luciana Melo ${ }^{2}$

ROCHA, Marizete Oliveira. MARTINS, Luciana Melo. Prejuízos psicossociais causados pelo vitiligo: A importância de um olhar para o corpo. Revista Científica Multidisciplinar Núcleo do Conhecimento. Ano 05, Ed. 12, Vol. 02, pp. 163-178. Dezembro de 2020. ISSN: 2448-0959, Link de acesso: https://www.nucleodoconhecimento.com.br/psicologia/vitiligo

\section{RESUMO}

O vitiligo é uma dermatose que causa manchas brancas na pele, possui formatos e tamanhos diferentes, surge em qualquer parte do corpo e pode levar a desfiguração estética, além de causar prejuízos psicossociais na vida do paciente acometido. Sem uma forma de prevenção e etiologia indefinida, o vitiligo não faz distinção de gênero, idade e etnia, pode afetar todos os tipos de pele. Não é contagioso e não compromete a funcionalidade do indivíduo, se apresenta como umas das dermatoses mais perturbadoras na descrição da literatura e causa sentimentos autodepreciativos. É importante que o tratamento seja integrado, envolvendo profissionais de saúde comprometidos com o bem-estar psicossocial do paciente dermatológico. O objetivo foi o conhecimento dos prejuízos psicossociais causados pelo vitiligo em seus acometidos. Metodologia: Revisão bibliográfica, inclusão- Trabalhos publicados de

\footnotetext{
${ }^{1}$ Acadêmica do curso de Psicologia na Faculdade Morgana Potrich (FAMP), MineirosGO, Brasil.

${ }^{2}$ Mestre em Psicologia pela Universidade Católica de Brasília, docente na Faculdade Morgana Potrich (FAMP), Mineiros- GO, Brasil.
} 
2002 a 2016. Foram excluídos os que não contemplavam o objetivo do estudo, seguindo da análise dos conteúdos selecionados e análise dos resultados. $\mathrm{Na}$ seleção, foram escolhidos os trabalhos cujos objetivos evidenciaram consideráveis e inúmeros prejuízos psicossociais a esses pacientes em vários contextos, marcando seus comportamentos como: vergonha, depressão, ansiedades, desamparo, tristeza, isolamento social, dificuldades nas relações e no trabalho, idealização suicida, entre outros. Daí a necessidade de um novo olhar na compreensão e empatia dos profissionais de saúde envolvidos no tratamento do paciente com afecção cutânea.

Palavras-chave: vitiligo e tratamento, efeitos psicossociais, corpo na psicanálise.

\section{INTRODUÇÃO}

Segundo a literatura, vitiligo é uma afecção cutânea que se apresenta com máculas brancas em algumas localizações da pele (ROSA; NATALI, 2009; SILVA et al., 2007). A forma e o local que se encontram as manchas dão origem a sua classificação (VIZANI et al., 2014). Quanto ao tratamento, são oferecidas várias formas, embora possa ser lento e nem sempre bem-sucedido, entre eles estão os medicamentos via oral, terapia com agentes físicos como, por exemplo, o laser Excimer, restauração do pigmento da pele e também cirurgias com transplante de melanócitos. É comum as pessoas que possuem esta afecção se queixarem do preconceito e do estigma vivenciado frequentemente, sendo estas umas das maiores dificuldades enfrentadas por estes pacientes (SILVA et al., 2007).

Apesar de não ser contagioso e não comprometer a funcionalidade do indivíduo, o vitiligo é uma das doenças de pele que se apresenta como umas das mais perturbadoras na descrição da literatura, pois a lesão costuma causar em seus acometidos sentimentos como: vergonha, ansiedade, tristeza, insegurança, desamparo, além de quadros como isolamento social e depressão, podendo chegar à idealização suicida (NETO et al., 2015). Contudo de acordo com Nogueira; Zancanaro; Azambuja (2009) as máculas são considerados por alguns profissionais da área médica, como uma questão apenas estética por não comprometer a saúde física do indivíduo e acabam negligenciando um fator de grande relevância como os prejuízos 
psicossociais desse paciente, que vivencia o desafio em se aceitar e ser aceito socialmente.

$\mathrm{Na}$ visão psicanalítica, dermatoses crônicas podem ser sugeridas como doenças somáticas, em que o corpo é um meio ou veículo a satisfação pulsional. Esse mesmo corpo passa também a ser veículo ou meio de expressar a dor e o sofrimento, assim, o corpo biológico não é o objeto de estudo da psicanálise, mas sim o que está no inconsciente deste corpo (FERNANDES, 2003). De acordo com Piera (1991) o corpo se manifesta através de vários sinais, fazendo se visível. O corpo manifesto pronunciando um corpo latente que permaneceu oculto toma então a emoção e o sofrimento somático como os mensageiros especiais do psiquismo em suas manifestações no plano somático. Segundo Weinman; Petrie; Morris (1996) cada paciente possui uma representação de sua afecção que é única, estes autores afirmam que $\mathrm{o}$ indivíduo com dermatose possui suas individuais crenças sobre a identidade, causa, duração e a cura da sua afecção, daí a importância de um tratamento integral, pois o tratamento clínico e psicoterápico contribuirá com maior eficácia no bem-estar psicossocial deste paciente. Para tanto é importante que o profissional conheça a forma como a vida deste indivíduo pode ser afetada pela dermatose, o real contexto que ele está inserido e as estratégias que poderão auxiliálo a enfrentar situações do cotidiano (PEREIRA; OLIVEIRA, 2012).

A justificativa acadêmica desta pesquisa foi a geração de conhecimento acerca do vitiligo, além de proporcionar uma reflexão sobre a importância do acompanhamento psicoterápico em pacientes com esta afecção cutânea. A justificativa para a sociedade foi a possibilidade de trazer informações sobre os aspectos desta dermatose pouco conhecida socialmente, que por esse motivo pode causar menosprezo inadequado e impróprio ao indivíduo acometido. Esta é uma pesquisa bibliográfica com abordagem qualitativa, em que o objetivo geral consistiu na busca pelo conhecimento dos prejuízos psicossociais causados pelo vitiligo na vida de seus acometidos. 


\section{METODOLOGIA}

Optou-se pela revisão bibliográfica com abordagem qualitativa por considerá-la um instrumento de pesquisa científica que se baseia em evidências de estudos já elaborados e publicados. De acordo com Gil (2008), a pesquisa bibliográfica é um estudo que se desenvolve baseada em materiais científicos já elaborados, principalmente em livros e artigos. Segundo esse autor, a pesquisa pode optar por uma abordagem que irá trilhar, no caso da abordagem qualitativa, seu foco não é analisar dados métricos e sim o conhecimento e compreensão de um grupo social, organização, entre outros.

Foram seguidos os seguintes passos metodológicos: de início selecionou-se artigos para a revisão que abordassem assuntos como: $O$ que revelam as publicações nacionais e internacionais sobre os prejuízos psicossociais causados pelo vitiligo na vida de seus acometidos? Encontrou- se 202 artigos, após se estabeleceu os critérios para a seleção da amostra. Foram critérios de inclusão do material, artigos publicados no período de 2002 a 2016, salvo clássicos, que utilizassem a temática do vitiligo e dos prejuízos psicossociais causados pelo vitiligo com resumos e textos disponíveis na íntegra via internet. Os critérios de exclusão foram artigos publicados fora do período aqui estabelecido, também aqueles que não contemplavam o objetivo deste estudo e acesso on-line indisponível ou de leitura não gratuita. Após a análise do conteúdo de 37 trabalhos selecionados, seguiu-se para a análise dos resultados. A coleta de dados foi por meio de busca on-line no site da Biblioteca Virtual em SaúdeBVS, selecionando-se as bases de dados: Scientific Electronic Library Online-SciELO, Literatura Latino-Americana e do Caribe em Ciências da Saúde- LILACS), United States National Library of Medicine -PubMed e Google acadêmico. Os artigos na íntegra foram obtidos nas bases de dados citadas acima e utilizaram-se os descritores: Prejuízos psicossociais do vitiligo, afecções cutâneas com efeitos psicossociais, tratamento do vitiligo, o corpo na psicanálise.

A metodologia seguida foi "bola de neve" (DEWES, 2010), na qual através das referências bibliográficas dos artigos que foram analisados, acessou- se outros com temas também afins. 


\section{REVISÃO BIBLIOGRÁFICA}

\subsection{VITILIGO}

O vitiligo é uma afecção cutânea que se caracteriza pela perda da tonalidade natural da pele e causa máculas acrômicas (SILVA et al., 2007), apresenta tamanhos e formatos desiguais. Pode surgir em qualquer parte do corpo, especialmente rosto, mãos, cotovelos, pés e joelhos. Com possibilidade de leucotriquia que é descoloração em pelos, independente de gênero, idade e etnia. Existem dois grupos de classificação do vitiligo: localizado e generalizado (VIZANI et al., 2014). No localizado, surgem manchas no mínimo em três partes do corpo. Este grupo de vitiligo se divide em três tipos: segmentar, onde as manchas aparecem no formato de faixas em um só lado do corpo; focal, onde as máculas aparecem no mínimo em três localidades do corpo, este é o tipo mais comum; e o tipo mucosas, que se dá apenas nas genitais e nos lábios (STEINER et al., 2004).

Quando o focal toma uma proporção em quase todo corpo, caracteriza assim o segundo grupo, sendo este o generalizado que se subdivide em quatro tipos: o vulgar, que possui formas simétricas e em várias partes do corpo; o misto que se caracteriza pela mistura de vulgar e segmentar; universal que é raro e atinge mais de $70 \%$ da pele e por último o tipo acrofacial que aparecem manchas somente nas mãos, pés e rosto. Alguns autores (ROSA; NATALI, 2009), ressaltam que a prevalência mundial estimada desta dermatose é de aproximadamente $1 \%$, mas a literatura apresenta uma variação de $0,5 \%$ até $4 \%$ nos mais variados países do mundo. Sua etiologia ainda não é comprovada definitivamente, embora, várias teorias tentam explicar a verdadeira origem do vitiligo, nenhuma conseguiu elucidar completamente sua real causa.

Muitos pacientes atribuem o início do vitiligo a um intenso estresse emocional vivido anteriormente, como perda de pessoas muito próximas, separação ou morte. Mesmo assim a maioria da literatura sobre esta afecção prioriza apenas por questões médicas exclusivamente, necessitando assim de mais estudos acerca desta teoria (MÜLLER; RAMOS, 2005). 
De acordo com Geremias; Viana (2009) além das máculas brancas existe também pele normal simultaneamente em uma mesma pessoa, inicialmente com manchas hipocrômicas[3] que em seguida se tornam acrômicas[4] onde as bordas são bem definidas e hiperpigmentadas, sendo clinicamente impossível prever a extensão e o formato das lesões.

Um exame muito útil que permite verificar a extensão da lesão e torna a afecção claramente evidente é o exame elaborado pela luz de Wood (SAMPAIO; RIVITTI, 2007). Este exame reflete na pele acometida uma luz branco-azulada, que é muito eficaz no diagnóstico da afecção menos aparente a olho nu e favorece o diagnóstico precoce e consequentemente o acompanhamento terapêutico do paciente. Tornandose necessários também exames laboratoriais, como o de glicemia e anticorpo, para um diagnóstico mais preciso (AZULAY et al., 2007). Quanto às observações microscópicas, o paciente pode se submeter a uma biopsia de pele se for necessário, a fim de eliminar a probabilidade de doenças que também podem levar a hipopigmentação como no caso da hanseníase (BORTOLOSO; SANTOS, 2009). Ficando este critério de diagnóstico complementar a cargo do dermatologista. Após o diagnóstico, o ideal é que se inicie o tratamento e para isso é preciso levar em consideração as técnicas mais apropriadas, as vantagens e desvantagens ao portador, pois o tratamento é individual (PEREIRA; OLIVEIRA 2012). Além de tratamentos medicamentosos, existem outras alternativas como: terapia com agentes físicos como por exemplo o laser Excimer, restauração do pigmento da pele e também cirurgias com transplante de melanócitos (VISANI et al., 2014).

Sampaio; Rivitti; Evandro (2007) afirmam que quando o paciente possui mais de $70 \%$ da pele acometida, o indicado é a despigmentação que se torna definitiva, pois ela destrói os melanócitos. Esta segunda linha de tratamento é indicada somente para adulto, devido sua melhor capacidade de assimilação, pois o procedimento irá alterar a fisionomia do paciente de maneira precisa e definitiva, sendo para toda vida os cuidados com a exposição solar, devendo sempre utilizar proteção (ZANINI; MACHADO FILHO, 2004). A realidade da pessoa acometida por vitiligo geralmente é 
repleta de desafios, além do enfrentamento da dermatose, ainda se depara com relevante preconceito e estigma social.

É comum as pessoas que possuem esta afecção relatarem serem vítimas do preconceito e do estigma vivenciado frequentemente (SILVA et al., 2007). Ao longo da história, seu termo de origem cuja palavra latina Vitium, que significa "marca", "defeito", "mancha", possibilitou o acometido pelo vitiligo ser visto como manchado, marcado, defeituoso ou sem pureza, nesse contexto confundia-se às vezes o vitiligo com outras doenças desfigurastes (ANNA et al., 2003). O velho testamento apresenta menção a várias doenças de pele com manchas brancas, juntas na palavra hebraica Zoraat, que, no grego tem como significado "lepra". Essa desordem entre ambas as doenças de pele colaborou relevantemente para o preconceito em relação as manchas, o que possibilitou ainda mais a discriminação com os acometidos de vitiligo, passando a identificar estas pessoas com o sentido figurativo de suas dermatoses (ISSA, 2003).

Segundo Anna et al. (2003) em afecções de pele como o vitiligo, o estigma é registrado no paciente como se suas marcas precisassem revelar ou reconhecer algo de sua natureza, demonstra-se assim uma considerável falta de informação social que geralmente é causada pela deficiência na comunicação transmitida. Apesar de nossa sociedade ser bem desenvolvida em relação a novas tecnologias e também em informações, esta situação ocorre devido à falta de interesse social em buscar as informações corretas e também das políticas públicas que não oferecem condições de suprir essa necessidade, como consequência, gera-se uma visão contraditória do que realmente é a dermatose (NETO et al., 2015). Afecções como o vitiligo muitas vezes estão associados a idéia popular de sujeira e o que é sujo logo é contagioso e sendo assim não é bonito e então deve-se manter afastado. O preconceito é um dos principais problemas enfrentados pelas pessoas acometidas pela afecção em questão, pode agravar o seu quadro e diminuir a eficácia do tratamento (SILVA et al., 2007).

Segundo (NETO et al., 2015) apesar da dermatose não ser contagiosa, muitos acometidos por esta afecção, sofrem com a discriminação de uma sociedade leiga, 
que insiste em julgá-los por sua aparência. O convívio entre pacientes com vitiligo e sociedade podem influenciar negativamente ou positivamente na vida psicológica do acometido, dependendo das atitudes das pessoas que o cercam.

Para Goffman citado por Szabo; Brandão (2016) um indivíduo poderia ser inserido naturalmente na relação social, porém por possuir um traço que se destaca e chama atenção, acaba afastando do outro que não considera seus vários atributos. Relata ainda que as imperfeições físicas estão entre os estigmas nos quais inserem os acometidos por vitiligo, que além de serem discriminados e considerados inferiores, o paciente pode acabar concordando que é inferior após perceber que os padrões sociais não o enquadram e que os outros não o vêem como igual. (TELLES; BLOC; EVANGELISTA, 2008) Existe ainda o auto estigma, que ocorre quando os pacientes estigmatizados identificam essas concepções contra si, passando a sentir culpa por esta situação. O sentimento de vergonha faz com que o indivíduo incorpore este julgamento social para si mesma, justificando-o. O sofrimento vivenciado pelo preconceito pode fazer com que a pessoa com dermatose tenha medo de seguir o tratamento e acabe tentando esconder a afecção que possui. Assim, a percepção do senso comum referente as dermatoses têm uma estreita relação com valores morais reproduzidos socialmente. Ainda de acordo com esse autor, o estigma e preconceito vivenciado por algumas pessoas com afecções cutâneas, envolvem as relações sociais, trabalhistas e familiares.

Neste sentido os acometidos de vitiligo, vivenciam experiências que podem causar inúmeros prejuízos psicossociais, convivem com a doença como: "um castigo", "feio", "sofrimento", "ruim", sentem- se discriminados, vítimas do preconceito e curiosidade. Doenças de pele que provocam lesões costumam causar em seus acometidos inúmeros constrangimentos como sentimentos de inferioridade, ansiedade, tristeza entre outros, surge assim o desafio em se aceitar e ser aceito. Atualmente a pele é considerada socialmente como um relevante requisito de beleza e possui considerável atribuição de valor social, imperfeições como rugas, manchas, acnes, cicatrizes e celulites, são consideradas marcas indesejáveis. 
Na sociedade liberal do século XXI, o cuidado com o corpo em busca de saúde e da beleza perfeita são rotinas e se tornam cada vez mais comportamentos compulsivos, isso demonstra como os indivíduos com mais frequência pensam e agem de forma a buscar a perfeição a qualquer custo (ROSA et al., 2009). É no corpo que se atingem as estratégias de poder, tornando-o objeto de investimento social que se torna uma passagem à produção das diferenças que se espalham na atualidade por meio da grande valorização de símbolos da saúde, beleza, qualidade de vida e também felicidade, na busca de igualar-se aos modelos físicos e assim é cada vez mais frequentes corpos siliconados, projetados, sarados, bem definidos, magros e esbeltos que, com rigor se submetem a um padrão de beleza imposto socialmente e determinam a aparência física enquanto símbolo do cuidado corporal (BASTOS et al., 2013).

O acometido de vitiligo não atende às exigências de uma pele perfeita e este é um dos requisitos impostos para ser bonito e bem sucedido. Seu corpo carrega as lesões de uma afecção que não tem compromisso algum com os padrões estéticos culturalmente e que, mesmo aparentemente inofensiva, quando em conflito com esses padrões gera complicações psicossociais (GOLDENBERG, 2005). É evidente na atualidade em que vivemos, onde a busca pela "perfeição" da beleza externa é altamente valorizada, de modo que as doenças de pele têm em seu caráter o estigma potencializado. Os padrões de estética e beleza impostos pela sociedade atual são bem delimitados, e as pessoas em sua maioria esforçam-se, para alcançá-los. Em pacientes com afecção cutânea, o sentimento de inadequação e o estigma vivenciado são claramente evidentes diante dessas exigências de "normalidade". A sensação de sentir-se discriminado por sua aparência física acompanha o paciente constantemente, causando grande insatisfação consigo mesmo devido a forma como o outro o vê, portanto, a adaptação a afecção se torna um foco causador de estresse (SILVA; MÜLLER, 2007).

A pessoa acometida com a afecção em questão, não queria ser diferente e sim se padronizar igualando conforme a estética que predomina e se misturar igualmente aos demais, afim de não ser exposto ao olhar alheio podendo exercer sua "invisibilidade" 
junto à multidão, como ressaltam Szabo; Brandão (2016). A discriminação vivenciada frequentemente traz consequências como os prejuízos psicossociais, uma dificuldade a mais para esses pacientes.

\subsection{PREJUÍZOS PSICOSSOCIAIS}

Os prejuízos psicossociais nesses pacientes são explicados pelo fato da pele ser o órgão mais extenso do corpo humano, mais exposto aos olhos das pessoas e consequentemente a julgamentos (LUDWIG et al., 2009). É comum o paciente expressar sentimentos como insegurança, desamparo e ansiedade, além de quadros como isolamento social e depressão por não compreender como a doença se desenvolveu em seu organismo (CORREIA; BORLOTI, 2013).

Para Vizani, et al. (2014), os acometidos pelo vitiligo podem desenvolver em consequência desta afecção: alterações de personalidade, baixa autoestima, estresse e também interferência nas relações sexuais devido ao constrangimento de suas lesões. Pelo fato de ser habitualmente confundida com outras doenças de hipopgmentação, algumas pessoas associam ao contagio à falta de higienização, podendo assim, causar o afastamento deste paciente do convívio social, pois a maneira de ver o vitiligo tem sérias consequências, o que causa sentimentos auto depreciativos que podem levar o acometido de vitiligo a sentir medo social e vergonha (DIAS, 2005). Ainda de acordo com esse autor, doenças de pele afetam relevantemente os relacionamentos e comunicação deste individuo, além de estressores psicossociais, como perdas, ansiedade, desemprego e baixa autoestima.

As lesões impactam de tal forma na qualidade de vida e emocional do paciente, que em alguns casos pode chegar à idealização suicida (LAYEGH et al., 2010). Para Ludwi et al. (2008), não importa o local que estejam situadas as lesões, tanto visíveis como em mãos, braços e face, ou no restante do corpo, caso o paciente se sinta exposto ao olhar do outro o prejuízo será o mesmo. De acordo com Nogueira; Zancanaro; Azambuja (2009) o vitiligo é considerado por alguns profissionais da área médica como uma questão apenas estética, pelo fato de não ser transmissível e não comprometer a capacidade funcional do indivíduo, onde não há lesões musculares ou 
ósseas e apenas o comprometimento estético da pele. Sendo assim acabam negligenciando um fator de grande relevância como os prejuízos psicossociais desse paciente, a dermatose possui um efeito consideravelmente devastador na autoestima do acometido, uma vez que seu corpo teve alterações estéticas não agradáveis a si nem aos padrões sociais.

\subsection{O CORPO NA PSICANÁLISE}

A pele é o espelho do funcionamento do organismo: sua textura, cor, temperatura, umidade, secura e todos os seus demais aspectos refletem o estado psicológico e fisiológico de cada indivíduo, como assegura Montagu (1988). A pele recebe não apenas sinais do ambiente como frio, calor, entre outros, ela capta ainda sinais do mundo interno, como no caso das emoções. Além de demonstrar o estado exterior e interior dos órgãos, a pele evidencia também processos e reações psíquicas em geral, é o envelope do corpo, assim como este envelopa o psíquico (ANZIEU, 1989). Ela é como uma barreira dentro-fora, eu e o outro, eu e o mundo, assim, age em forma de abrigo a individualidade e "ao mesmo tempo que protege, também ela é o limite que se expõe" (STRAUSS, 1989).

Se observa que nos tempos atuais emergem inúmeros modos das pessoas buscarem uma pele para o seu "eu" desalojado, como: o uso epidêmico dos anabolizantes, do botox, das próteses de silicone, da intensa organização da aparência de si por meio de tratamento estéticos, na expectativa de encontrar no olhar do outro o alojamento e a morada do "eu". Também como símbolo de uma perfeição ideal, que incansavelmente procura se alcançar na atualidade, o corpo é hiperinvestido, mas com frequência é fonte de frustração e também de sofrimento, "constituindo-se como um meio de expressão do mal-estar contemporâneo" (FERNANDES, 2003). Ainda segundo a autora, o corpo é um meio ou veículo a satisfação pulsional, esse mesmo corpo passa também a ser veículo ou meio de expressar a dor e o sofrimento, assim, o corpo biológico não é o objeto de estudo da psicanálise, mas sim o que está no inconsciente deste corpo, esse percurso pode ser observado com facilidade quando se pensa nos impasses da clínica psicanalítica, principalmente em pacientes ditos 
somáticos, pois eles necessitam de um aprofundamento da referência psicanalítica (FERNANDES, 2003).

A pulsão não é energia física e sim uma energia pulsional, uma emoção que não foi vivenciada corretamente e por isso foi recalcada no inconsciente, onde se encontra em estado bruto e se escoa através da representação em forma de sintoma orgânico, sem que para isso se apareça de forma direta. Pois sabe se que algo representado em um lugar, em outro deve estar o seu original (FERNANDES, 2003). De acordo com Piera (1991) o corpo se manifesta através de vários sinais, faz se visível. O corpo manifesto pronunciando um corpo latente que permaneceu oculto toma então a emoção e o sofrimento somático como os mensageiros especiais do psiquismo em suas manifestações no plano somático. A emoção é uma vivência que o "eu" tem consciência, ou seja, sabe o que a provocou, é algo ouvido, visível que modifica o estado somático daquele que experimenta e divide uma identificação com quem a compartilha. Por exemplo: uma doença que estava oculta e se manifesta causando sofrimento, essa situação pode provocar uma reação em quem testemunha, assim dizemos que dor e emoção são "relacionais", fazem uma conexão entre corpo sensorial e um corpo relacional. São mensageiros então porque falam das suas próprias manifestações somáticas e ainda possibilitam diferentes formas de reações dos outros.

Um fato ligado a dor ou a emoção pode romper uma história singular e a construção que a pessoa fará dessa ocorrência dependerá não apenas de sua conexão particular entre seu corpo e sua psique, mas também da resposta em que sua dor ou emoção vão causar no outro. Sucessivas representações vão sendo formadas no corpo pela emoção e pela dor e se articulando com motivações inconscientes, assim, juntas decidirão como o sujeito atribuirá o sentido histórico dos acontecimentos de sua vida. A história do indivíduo é o roteiro das marcas relacionadas a dor e também da emoção em seu próprio corpo, esta é sua identidade e a história que ele escreveu em que atribui sentidos a suas marcas se torna um contexto que nunca se completa. Essa identidade corporal que parece sempre definida, precisa se manter sempre em aberto, sempre inacabada para que o indivíduo aceite as mudanças impostas pelo tempo sem 
que perca sentido da permanência. Ainda de acordo com Piera (1991), essa possibilidade do outro ser sempre mutável, estar presente ou ausente, infligir prazer ou dor, submete o "eu" a situação de também ser auto modificável, mas para sustentar a diferença é preciso que o " eu" se auto represente como pólo estável dessa relação de investimento e para continuar essa ligação irá depender da possibilidade de negociação do "eu" entre as demandas do id e do outro, sendo assim o corpo um mediador entre a psique e o mundo.

Pines (1980) relata que, no nascer a pele já é o mais completo órgão de percepção, sente as mudanças do corpo da mãe aconchegante e caloroso, para um mundo externo frio. Dessa forma, a pele passa a ser o meio de contato físico e de também de resposta a emoções que vivencia o bebê, tanto de bem-estar quanto de angústia. Para o autor acima citado, a pele se torna uma fonte de comunicação pré-verbal, pois sentimentos não expressos podem ser além de vivenciados também observados. Quaisquer dificuldades nesta comunicação, independente da razão, poderá se resultar em frustração das necessidades infantis e poderá ser resultado por exemplo de dermatite infantil, ou até criar uma fixação neste contínuo desenvolvimento emocional. Os sintomas seriam então mensagens trazidas, da psique. Galiás (2002) diz que esses sinais ou sintomas devem ser compreendidos primeiramente antes de qualquer coisa, para só após então serem eliminados. A dermatose pode representar emoções não-resolvidas que apresentam como manifestações orgânicas. Então o sintoma vem como linguagem, manifestação simbólica, daquilo que permaneceu oculto (AZULAY; AZULAY, 1997).

\subsection{TRATAMENTO INTEGRADO}

Apesar de várias pesquisas ressaltarem a manifestação de conflitos inconscientes na pele, somente a partir do ano de 1980, que surgiu interesse dos médicos dermatologistas na delicada relação entre corpo e psique. Para Folks; Knney (1992) isso é principalmente devido à relação clara de prejuízos psicossociais, à baixa autoestima e ao estigma social em pacientes com afecções dermatológicas. É aí que a bidirecionalidade corpo/ psiquismo dá origem a um segmento da dermatologia, a psicodermatologia, que propõe entender e tratar o paciente de maneira integral. No 
entendimento dessa área, além do acompanhamento médico, é necessário se aliar ao acompanhamento psicoterápico, nas mais diferentes formas: psicoterapia de apoio, grupal, individual, comportamental, técnicas de relaxamento, grupos de auto ajuda, uso de drogas psicotrópicas como antidepressivos e ansiolíticos e o trabalho em conjunto do médico com o psicoterapeuta.

As intervenções com pacientes dermatológicos exigem um tratamento individual e único a cada paciente. Nogueira; Zancanaro; Azambuja (2009), destacam que para melhor atendimento ao paciente, o dermatologista precisa considerar um importante aspecto da afecção: os prejuízos psicossociais e oferecer uma abordagem de forma mais humanizada possível. Pois uma palavra errada, uma entonação infeliz, uma frase inadequada, pode ter resultados desastrosos para determinado indivíduo, o que acaba comprometendo seriamente o tratamento da dermatose.

Em um estudo desenvolvido por Müller; Ramos (2005), com 13 pacientes do sexo feminino, todas acometidas de vitiligo, tiveram como objetivo verificar a eficácia do tratamento integrado na repigmentação da pele lesionada, neste estudo 10 pacientes fizeram acompanhamento com médico e psicólogo por seis meses, destas, cinco receberam atendimento psicológico em grupo, as outras cinco receberam atendimento psicológico individual, as três demais receberam apenas o atendimento médico pelo mesmo período de tempo. Por fim, as pacientes que receberam acompanhamento integrado obtiveram um percentual de até $80 \%$ de repgmentação cutânea, enquanto as pacientes que receberam somente o acompanhamento médico tiveram até $20 \%$ do percentual de repgmentação. Portanto esse resultado evidencia a importância de um tratamento integrado em pacientes acometidos pelo vitiligo. É importante que o profissional conheça a forma como a vida deste indivíduo pode ser afetada pela dermatose, o real contexto que ele está inserido e as estratégias que poderá auxiliálo a enfrentar situações do cotidiano, para que possa atuar da melhor forma junto ao paciente, contribuindo então para um tratamento mais eficaz.

Weinman; Petrie; Morris (1996) ressaltam que cada paciente possui uma representação de sua afecção que é única, estes autores afirmam que o indivíduo com dermatose possui suas individuais crenças sobre a identidade, causa, duração e 
a cura da sua afecção. Tais representações refletem a resposta cognitiva de cada paciente para os sintomas e a dermatose, as respostas emocionais são processadas paralelamente à representação da afecção. Apesar do vitiligo ainda ser uma doença com poucos estudos no campo da psicologia é evidente a importância de um acompanhamento psicoterapêutico que promova o bem-estar deste paciente para melhores resultados no tratamento, fazendo- se então necessário, um atendimento integrado (PEREIRA; OLIVEIRA, 2012).

\section{CONSIDERAÇÕES FINAIS}

Desde a gestação de um bebê, a pele é seu primeiro meio de contato, é através desta que ele sente as sensações de calor e aconchego no útero materno. Ao nascer, as primeiras conexões externas desse bebê, também se dão através desse órgão, é por meio dele que a criança sentirá o toque, carícias e a temperatura do corpo de sua mãe, sendo assim, a pele desde sua origem é fonte de proteção, relação, comunicação, percepção e contato. Funciona como uma barreira que além de abrigo e amparo também o apresenta aos seus semelhantes e ao mundo, é através do olhar do outro que ele se reconhece, assim, buscando seu eu ideal por meio da imagem refletida através do outro, como um espelho.

A psicanálise utiliza elementos internos desse indivíduo para auxiliá-lo no enfrentamento daquilo que the causa sofrimento, como no caso do preconceito. Ouvir e acolher o indivíduo de forma singular, conhecendo todo seu histórico de vida, o que tem por trás desse sofrimento, como é para esse paciente lidar com sua afecção e consequências desta, o que the causa dor nesse real contexto. É importante que se conheça toda a singularidade do paciente, pois cada um possui uma forma de sentir e enfrentar suas dificuldades de uma forma única e exclusiva.

Para tanto a realidade do indivíduo acometido pelo vitiligo é repleta de desafios, além do enfrentamento da afecção, das dificuldades em expor suas emoções, ainda se depara com relevantes estressores psicossociais frequentemente. Embora a dermatose não seja transmissível, nem causa danos ao funcionamento físico do indivíduo, ainda sim deve se considerar um importante fator de grande relevância: o 
vitiligo é altamente prejudicial à vida psicossocial deste paciente e pode ser devastador em sua autoestima além de sua evolução ser clinicamente imprevisível, pode causar a desfiguração estética. Como foi evidenciado, o psicoterapeuta contribui de forma considerável juntamente com o dermatologista no tratamento do vitiligo, é preciso levar em consideração a melhor qualidade de vida do indivíduo em relação a sua alto aceitação e enfrentamento do preconceito, entre outras barreiras que podem surgir em decorrência dos prejuízos psicossociais causados pela afecção em questão.

Daí a necessidade de um novo contexto na compreensão e empatia dos profissionais de saúde em prol de um tratamento mais humanizado e integrado possível para com os pacientes dermatológicos. Faz se necessários mais estudos acerca do vitiligo no campo da psicologia devido à precariedade em relação à quantidade de trabalhos divulgados nesse contexto nacionalmente. É importante também levar em consideração a quantidade de relatos de pacientes que indicam que suas lesões surgiram após intensas situações de estresse emocional, além de que esse fator pode agravar a situação ou ainda prejudicar o tratamento. Sugere- se ainda, a necessidade de mais pesquisas que investiguem o vitiligo como um possível sintoma manifesto através do psiquismo. Pois além de ser uma dermatose já descrita desde a antiguidade e após várias teorias elaboradas na tentativa de explicar sua real origem, ainda assim, o vitiligo é uma afecção sem etiologia definida.

\section{REFERÊNCIAS}

ANNA. P.A.; BAZHUNI, N. F. N; CASTANHO, A. G.; GIOVANETTI, R. M.; SELVA, V.A. L; A expressão de conflitos psíquicos em afecções dermatológicas: Um estudo de caso de uma paciente com vitiligo atendida com jogo de areia. Psicologia: Teoria São Paulo V. 5 n.1 Jun. 2003.

ANZIEU, D. O.; Eu - pele. Casa do psicólogo São Paulo, 1989.

AZULAY, R; AZULAY, D. Dermatologia. Guanabara: Koogan, 1997. 
AZULAY. D. R; AZULAY. L; BONALUIA; LEAL. F; HANAUER. L., Afecções Dermatológicas de A a Z. In: - Atlas de Dermatologia da Semiologia ao Diagnóstico. $2^{\circ}$ Ed. Rio de Janeiro: Elsevier, 2007, p.719- 720.

BASTOS, W.; CASTIEL, L. D.; CARDOSO, M. H. C. DE A.; FERREIRA, M. S.; GILBERT, A. C. B. Epidemia de fittnes Saúde Soc. São Paulo, v.22, n.2, p. 485-496, 2013.

BORTOLOSO; ADRIANE; SANTOS, PEREIRA, V. L. Estudo de caso: influência dos raios ultravioleta no tratamento do vitiligo. UniBrasil grupo educacional. Paraná jan. 2009. p.1-13

CORREIA. K. M. L; BORLOTI. Convivendo com o vitiligo: Uma análise descritiva da realidade vivida pelos portadores Acta comportamentalia Universidade Federal do Espírito Santo. Espírito Santo v. 21 no 2, p. 227-240.Jul 2013.

DEWES, J. O.; Amostragem em bola de neve e respondent-driven samplig: uma descrição dos métodos. Universidade federal do rio grande do sul. Porto Alegre, 2013.

Disponívelem:<https://www.lume.ufrgs.br/bitstream/handle/10183/93246/000915046. pdf?sequence=1>. Acesso em: 07 de agosto. 2017.

DIAS. M. B, Vitiligo como sintoma. A dificuldade no contato com as emoções. Revista de psicanálise. n. especial. São Paulo, p 33-40, maio. 2005. Disponível em: $<$ htt://WWW.editora escuta.com.br/pulsional/esp05-06.pdf> Acesso em 20 fev.2017.

FERNANDES, M. H. Corpo- clínica psicanalítica, casa do psicólogo, Ed. $3^{\circ}$, São Paulo, 2003.

FOLKS, D.; KINNEY, C. The role of psychological factors in dermatologic conditions psychosomatic. v. 33, n. 1, p. 42-54, 1992. 
GALIÁS, I. Psiquiatria e Dermatologia: o estabelecimento de uma comunicação bidirecional. Junguiana: Sociedade Brasileira de Psicologia Analítica. V. 20, p. 5772, 2002.

GEREMIAS, R.;VIANA. E. A.; A caracterização do vitiligo e o uso de plantas para seu tratamento. $3^{\circ}$ Ed. São Paulo Revista de iniciação científica, 2009. Disponível em<htt://periódicos.unisc.net/índex.php/iniciaçãocientífica/article/view/47/42>Acesso em 22 fev. 2017.

GIL, A. C. Como elaborar Projetos de Pesquisa. 4.ed. São Paulo: Atlas, 2008, p. 4445.

GOFFMAN, E.; organizador. Estigma: notas sobre a manipulação da identidade deteriorada. Rio de Janeiro: LTC; 2008. Disponível em: https://edisciplinas.usp.br/pluginfile.php/92113/mod_resource/content/1/Goffman\%3B \%20Estigma.pdf. Acesso em 25 de fev. 2017

GOLDENBERG, M.; Gênero e corpo na cultura brasileira. Psicologia Clínica, PSIC. CLIN. Rio de Janeiro, VOL.17, N.2, P.65 - 80, 2005.

ISSA, C. M .B. M. Transplantes de melanócitos no tratamento do vitiligo: um processo terapêutico? Tese (Doutorado em Clínica Médica) - Universidade Estadual de Campinas, São Paulo 2003. Disponível em: http://www.bibliotecadigital.unicamp.br/document/?code=vtls000296357\&fd=y acesso em 20 de julho 2017.

LAYEGH, P.; ARSHADI H. R.; SHAHRIARI, S.; NAHJIDI, Y. A comparative study on the prevalence of depression and suicidal ideation in dermatology patients suffering Iranian Journal of Dermatology. Society of Dermatology 2010. Iranian.

LUDWIG, M. W. B.; OLIVEIRA, M. S.; MÜLLER, M. C.; MORAES, J. F. D. Qualidade de vida e localização da lesão em pacientes dermatológicos. Anais Brasileiros de Dermatologia, v. 84 n², mar/abril 2009. P.143-150. 
MONTAGU, A.; Tocar o Significado Humano da Pele. Summus São Paulo. 1988.

MULLER, M. C; RAMOS, D. G.; Psicodermatologia: uma interface entre psicologia e dermatologia. Tese (Doutorado em Psicologia Clínica), Universidade católica do Rio Grande do Sul, Brasília, 2005. Disponível em: http://www.scielo.br/scielo.php?script=sci_arttext\&pid=S1414$98932004000300010 \&$ Ing=pt\&nrm=iso. Acesso em 27 fev.2017.

NETO, A.T. M.; PINTO. F. O.; RODRIGUES. M. D.; SILVA.V.S.; Vitiligo: Uma doença que não é só de pele. Revista Interdisciplinar do Pensamento CientíficoFaculdade Metropolitana São Carlos.Ed 2, v. 1. n 1, p.250-288. Jul/dez 2015. D. O. I.

NOGUEIRA, L. S.C.; ZANCANARO, P. C. Q.; AZAMBUJA, R. D. Vitiligo e emoções. Anais Brasileiro de Dermatologia. Rio de Janeiro, 2009 v.84, n 1. p. 41-45.

PEREIRA. V. Q.; OLIVEIRA. G. G.; Vitiligo: fisiopatologia, discromias e tratamento. UniFil. Vi Congresso Multiprofissional em Saúde. 2012.

PIERA, AULAGNIER- Nascimento de um corpo, Origem de uma história. Buenos Aires, Paidós. Psicologia profunda, 1991.

PINES, D. Skin communication: early skin disorders and their effect on transference and countertransference. International Jornal Psycho-Analitic, v. 61, p. $315-323$, 1980.

ROSA, E. C.; NATALI, M. R. M. (2009). Vitiligo: um problema que não pode passar em branco. Revista Saúde e Pesquisa, Paraná. Jan./abr. 2009 v. 2, no. 1, p.119-126.

SAMPAIO; RIVITTI, S. A. Dermatoses por imunodeficiência primárias. In: Dermatologia. 3. ed. ; São Paulo: Artes médicas, 2007. p. 356-360.

SILVA, C. M. R.; PEREIRA, L. B.; GONTIJO, B.; RIBEIRO, G. B. Vitiligo na infância: características clínicas e epidemiológicas. Anais Brasileiros de Dermatologia, Minas gerais, 2007, v.82, $n^{\circ} 1$. P. 47-51. 
SILVA, J. D. T.; MÜLLER, M. C. Uma integração teórica entre psicossomática, stress e doenças crônicas de pele. Estudos de Psicologia, São Paulo, 2007, v. 24 n. 2, p. 247-256.

STEINER, D.; VILLAS, RT.; BEDIN, V; STEINER, T.; MORAES, MB. Vitiligo. Vitiligo epidemiological profile and the association with thyroid disease An Bras Dermatol. 2004; 79:335-51.

STRAUSS, G. Skin disorders. Baltimore: Williams Wilkins, 1989.

SZABO; BRANDÃO E.; "Mata de tristeza!":Representações sociais de pessoas com vitiligo Interface- comunicação, saúde, educação. Rio de Janeiro. 2016, v. 20 n² 2, p. 953-965.

TELLES, T. C. B.; BLOC, L. G.; EVANGELISTA, K. T. E.; Diferentes estigmas em diferentes doenças? In: III Congresso Internacional de Psicopatologia Fundamental e IX Congresso Brasileiro de Psicopatologia Fundamental, Niterói, 2008. em: <http://www.psicopatologiafundamental.org/uploads/files/iii_congresso/posteres/difer entes_estigmas_em_diferentes_doencas.pdf>. Acesso em: 25 de fev. 2017.

VIZANI. R. O; MAIA. F. S. M; VASCONCELOS. T. P.; PIMENTEL. S. L. G; NAKAOKA. V. Y. E. S.; KASHIWABARA. T. G. B. O vitiligo uma doença orgânica. Master Editora. Minas Gerais, mar/ mai 2014, v. 6, n. 3, p.47-52 .

WEINMAN, J.; PETRIE, K.; MORRIS, R. The illness perception questionaire: a new method for assessing the cognitive representation of illness. Psychology and health, v. 11 , p. 431- 465, 1996.

ZANINI, M.; MACHADO, F. C. C. D. A. S. Terapia despigmentante para o vitiligo generalizado com solução tópica de fenol $88 \%$. Anais Brasileiros de Dermatologia. São Paulo. V. 80, n 4, p. 415-416. Abr. 2014. 


\section{APÊNDICE - REFERÊNCIAS DE NOTA DE RODAPÉ}

3. O termo hipocromica é usado para designar manchas na pele que são mais claras que a própria pele.

4. Acrômica: mancha sem cor, incolor.

Enviado: Janeiro, 2020.

Aprovado: Dezembro, 2020. 